\title{
建筑城市更新与改造问题探讨研究
}

\author{
彭丹丹 \\ 南京大学 \\ DOI:10.18686/bd.v2i2.1234
}

[摘 要] 城市的发展是一个不断运动的过程, 就如生命的新陈代谢一样, 城市一般具有较强的活力, 但是发展中求新求变也 是城市进步的必然选择, 因此, 城市的更新和改造问题是城市规划,建筑设计等相关领域的重要工作内容, 也是城市发展过程 中的比较困难的方面。本文以城市更新和改造上的侧重点的差异为基本着眼点, 着重阐述了在建筑城市更新和改造问题中 的重点和难点, 进一步为城市更新和改造做出贡献。

[关键词] 城市更新;改造; 问题处理

随着经济的发展, 人民生活水平的提高, 城市的建设水 平也在逐渐向着更高的标准发展, 如何做好城市更新和旧 城的改造问题是具有深远的意义的。做好城市更新和改造 工作不是对过去的城市文化和历史的丢弃，而是一种积极 的转化,需要进行深人的研究。

\section{1 城市建筑改造模式及问题分析}

1.1 楼体改造

当前, 我国的楼体改造依然处在对建筑外观的处理上, 在处理时通常采用外立面贴砖和粉刷等方式,此外,屋顶坡 面的改造和室内外节能改造也较为常见, 而建筑自身的安 全隐患以及建筑的内部空间环境却没有得到很好的改良处 理。

\section{2 环境整治}

很多西方国家在建筑环境改造方面更加重视环境的绿 化以及社会环境的改进。而我国当前的环境整治重点主要 是道路的整修、绿化、商业网店的规划建设以及城市垃圾的 清理等。上述举措虽然能够优化建筑周边环境,但是其在时 效性上存在着明显的不足,整治效果不理想,此外在社会环 境的优化方面也没有采取积极的措施。

1.3 设施的完善

城市建筑设施更新和完善主要涵盖了门窗、落水管、电 气的改造和消防设施的更新等。但是由于产权归属的问题, 在设施更新方面主要将目光集中在公共空间基础设施的更 新和完善上, 而对建筑内部设施的改造和更新并不十分重 视。

\section{2 城市建筑改造中亟待解决的主要问题}

2.1 完善法律制度建设

当前, 我国在城市改造上并没有非常详细和完善的法 律及相关制度, 在实际的工作中也出现了众多不规范现象, 但由于法治建设的不完善,无法对其进行有效处理。因此,必 须要不断建设完善的法律制度以及规范条例, 此外还要按 照地区发展的实际情况来制定出更为科学的地方性法规条 例,进而提高城市建设改造的标准度和规范度。

2.2 创建科学的发展机制
当前,我国城建改造工程中,一般均为政府出台有关文 件,之后将其分配给工程建设的有关单位,进而履行自己的 职责,承担相应的责任与义务。这种改造模式会由于政绩的 影响而干扰建筑工程改造的实际要求, 同时这种机制还没 有充分地引入公众参与和多方监督协作的机制。所以必须 要改变这种现状,建立更加完善的发展机制,积极增强公众 的参与度, 同时还要采取有效措施加强公众自有资金的吸 引力,进而降低了对开发商的依赖度。

\section{3 我国城市建筑更新改造发展模式分析}

3.1 中式建筑物外形和内部空间改造

在建筑物外形改造中必须要做好工程加固和修复工 作,对建筑物的外层结构进行及时的处理。同时还要对使用 时间较长的墙体进行有效加固。当前主要应用钢结构框架 来保证结构的抗震性能。在建筑内部空间的改造中一般是 针对内部空间的使用功能进行适当的处理和改造。通常陈 旧建筑的面积不大, 内部使用功能也十分有限, 针对这一情 况可以采取加层、减层的方式来调整原有的户型结构,进而 增强内部空间的功能性。也可以将外部空间采取室内化的 方式处理,从而扩展室内空间。这种改造方式可以对空间进 行重新整合, 因此在公共建筑空间的改造中较为常见。在建 筑外观的改造中主要是在确保建筑现有形式的前提下对外 部的陈旧建筑采取不同方式予以处理, 进而更好地保证建 筑物的使用性能。加建主要可以分为两种形式,一种是横向 改造,一种是纵向改造。前者主要是利用相邻房间的隔离与 连接改变平面结构布局, 而后者主要是采用分层或加层的 方式来起到扩展空间的作用。拆除也具备不同的形式,主要 有减少楼层和底部架空。包裹处理方法一般是指将陈旧建 筑包裹在新建筑内部,不改变原有建筑的结构形式。

3.2 以环境整治为主导的更新方式

以环境整治为主导的更新改造是立足于建筑内外部环 境,通过道路绿化亮化,增加公用设施等方面,改善老城区的 环境。宏观的环境整治一般以区域为单位,从城市的角度,改 善区域的交通状况、自然环境,微观的环境指建筑环境,改善 建筑内部与外部的道路、绿化设施,方便人们的生活。 
3.3 采用生态措施和新技术改造为主导的更新方式

采用生态措施和新技术改造为主导的更新改造方式, 主要针对城市旧建筑的节能改造。通过采用生态节能新技 术, 实现对建筑体的保暖、隔热、防潮、采光、通风等进一步 完善。充分利用新能源,包括利用太阳能、风能等绿色新能 源, 在旧建筑顶部增加收集装置, 达到对太阳能的充分利用, 以及能源回收利用等节约能源系统, 如雨水废水回收、废热 回收等。我国城镇现在住宅总量已达到 40 亿平方米, 本世 纪已经开始进人大修的高峰期。主要以住宅建筑为主要改 造项目, 因此研究制定符合我国国情的城市建筑改造发展 规划与模式是非常重要的。

\section{4 城市更新改造中的几大关系的处理}

4.1 城市更新与文化保护的有机统一

需要进行改造的城市一般都具有一定的历史文化背 景, 一个城市的文化背景和历史建筑是这个城市在特定的 历史阶段的印记, 是那个时代的政治、文化和经济的整体融 合后的体现,这些才是这个城市的记录者, 是一个城市区别 于其他城市的名片, 具有不可估量的价值, 是一个城市的最 宝贵资源,并且还是不可再生的,这些城市历史文化的产物 才是一座城市的鬼力体现。

城市的发展规划过程中总会出现一个两难的问题, 就 是如何平衡城市的旧城改造和城市的文化保护。历史用血 淋淋的教训告诉我们, 城市改造中如果不重视文化的保护, 这座城市也就失去了其本来的价值和鬼力, 当人们反思过 来时, 文化补救已是来不及的。笔者认为, 旧城改造工作必须 兼顾好城市的文化保护。二者都有非常重要的意义,都是城 市发展过程中不可缺少的, 保护城市文化这件事情不能有 任何的余地,也绝不能杀鸡取卵。因此, 在进行文化保护的大 原则下进行旧城改造方案的设计, 旧城改造的实施还要对 文化保护起到积极的推进作用, 使二者的关系紧密起来,而 不再是对立的情况。一方面要对需要改造的城区的文化背 景进行研究, 对设计的艺术方式进行分析, 确保在进行改造 时还能做到艺术手法和文化背景的完美契合。一方面在进 行改造时要渐进式, 改造工作不能只为了求快, 更应该兼顾 到文化的保护, 只有这样才能在实际的城市更新中做到双 赢。

\section{2 原有建筑和居民居住环境的和谐}

为了努力的实现 2020 年的全面建成小康社会的伟大 目标, 并满足人们对美好生活的期望, 我们的旧城改造工作
一方面要严格的做好历史建筑的文化保护工作，为市民的 生活提供物质和精神的建设, 让居民的居住环境更增添魅 力和美感; 在做好保护历史建筑的前提下, 对老城区的房屋 进行有计划、科学的改造, 要合理安置原住居民的生活, 维护 好社会的稳定,城市的发展是为了让居民的居住更舒适、更 便利,所以不管何时都要做好这项工作,保障人民的基本生 活稳定性和安全性。此外, 在旧城更新改造中,如何让旧城不 沦落为商业街而且一个充满生活气息的街区也是值得探讨 的。

4.3 局部城市形态和整体城市形态之间的协调

在旧城改造的工作中, 处理好城市局部和整体的关系 是非常重要的,处理不好就会出现两种不良的后果,一方面 是城市改造后的城市新风貌与国家的实际情况不相符合, 这样就会对整个城市的形态协调产生了极大的破坏力; 一 方面是改造后的城区形态与周边的没经过改造的城市形态 不相匹配, 视觉直观感受具有较强的反差, 没有整体协调性, 这样也就破坏了城市的整体形态。因此,城市的局部和整体 的协调是非常重要的, 要做好这一工作就要着眼于城市文 化本身, 在原有的建筑风格和文化背景下进行规划和创作, 不能脱离实际情况和需求, 也不能一味的盲目模仿或生搬 硬套,要在城市旧城改造中做到新旧的完美融合和创作。

\section{5 结束语}

随着城市的不断发展, 人们生活水平的逐步提高, 城市 改造是不可避免的城市规划主题, 而这又是一项任重而道 远的任务,需要政府和社会各方面的力量共同努力, 在进行 城市更新和改造过程中, 如何平衡城市改造和文化风貌的 保护是一项亟需深人思考的问题。为此, 在城市的发展过程 中, 我们要完善好城市设计中的方方面面的问题, 做到立足 于城市本身的特点, 以改善人民生活环境为根本, 积极的做 好城市更新和旧城改造的系列工作。让城市的发展更美好, 让人们的生活更幸福。

\section{参考文献:}

[1]崔青.上海三林滨江城市更新实践和技术探究[J]. 住宅科技,2018,38(02):20-25.

[2]庞智. 从空间改良到活力营造一一英国城市更新的 研究思考 [J].上海城市规划,2016,(06):67-74.

[3] 焕新之路——城市更新与既有建筑改造[J].城市住 宅,2017,24(04):5. 